\title{
Road Bank Estimation for Bus Rollover Prediction
}

\author{
Guizhen Yu, Di Wang, Qin Li, Pangwei Wang and Yunpeng Wang* \\ School of Transportation Science and Engineering, Beihang University, Beijing 100191, China
}

Received: 5 Feb. 2013, Revised: 6 Jun. 2013, Accepted: 7 Jun. 2013

Published online: 1 Sep. 2013

\begin{abstract}
This paper presents an estimation of a bank angle for bus rollover prediction when the bus is driving around a curved road. An estimator for the dynamic road bank, as well as vehicle sideslip angle estimation, using the dynamic simplex algorithm is designed to consider the influence of road bank on rollover prediction. An application of the estimated bank angle in rollover prediction was then provided. The proposed estimator is evaluated by TruckSim software, and simulation results show that the estimator can generate acceptable bus rollover prediction in typical scenarios.
\end{abstract}

Keywords: Roll stability; rollover; velocity warning.

\section{Introduction}

Many researchers have investigated transportation safety topics from all fields [1-5]. Vehicle rollover is the most serious among all types of fatalities [1]. Rollovers cause nearly $33 \%$ of all deaths in bus crashes, according to previous statistical data [6]. Buses have a higher rate of rollover because of its higher center of gravity (CG) compared with other types of vehicles. Rollovers cause approximately $15 \%$ of serious injuries and $20 \%$ to $25 \%$ of fatalities in the US [7]. Therefore, developing effective rollover prevention systems would be of great importance to improve highway safety. Several studies have been conducted on rollover threat detection [1]. These rollover detection methodologies highly depend on vehicle lateral acceleration [8]. Road bank has a direct impact on vehicle dynamics and lateral acceleration measurement. Road bank needs to be calculated first to minimize the estimation errors of vehicle states. Although road bank disturbance has a significant effect on vehicle state estimation, this requirement has been neglected in the academic discussion of lateral velocity estimation [11] and lightly portrayed as information already available in the discussions of industrial applications [12]. Bank angle was directly obtained from some sensors [9]. Several previous studies have analyzed the influence of bank angle on roll stability when a vehicle stops on a bank angle [10]. However, reference [11] only studied roll stability on a static bank angle. Estimation method is often used for estimating state parameter because of expensive sensors or inconvenient installation in vehicle intelligent and safety fields [11, 19]. Although the analysis on how the road bank angle affects roll stability is found in the literature, most of the rollover warning algorithms are designed without considering dynamic road bank estimation. In this paper, we mainly discuss dynamic road bank estimation. The rest of the paper is organized as follows. Road Bank Estimation is presented in Section 2. In Section 3, the proposed algorithm is evaluated using TruckSim [13]. Section 4 discusses how to estimate bank angle on rollover prediction. Section 5 presents the conclusions.

\section{Road Bank Estimation}

\subsection{A 2-DOF Vehicle Model}

A 2-DOF (DOF, Degree of Freedom) vehicle model with 4 wheels is presented in Fig. 1. The model is used for online computation of lateral acceleration and yaw rate based on vehicle states and road friction. Considering road bank angles, equations governing the lateral and yaw motions of a vehicle are as follows [14]:

$$
\begin{gathered}
m(\dot{v}+r u)=\left(F_{y f l}+F_{y f r}\right) \cos \left(\delta_{f}\right) \\
+\left(F_{y r l}+F_{y r r}\right)+m g \sin \phi_{B} \\
I_{z} \dot{r}=a\left(F_{y f l}+F_{y f r}\right) \cos \left(\delta_{f}\right)-b\left(F_{y r l}+F_{y r r}\right) \\
-\frac{t_{w}}{2}\left(F_{y f l}-F_{y f r}\right) \sin \left(\delta_{f}\right)
\end{gathered}
$$

\footnotetext{
* Corresponding author e-mail: Yugz@buaa.edu.cn
} 
Note that $V_{G}$ is the vehicle velocity at the CG, which is the resultant vector of longitudinal and lateral velocities denoted by $u$ and $v$, respectively. Tire slip angles can be determined according to kinematic relationships (Fig. 1),

$$
\begin{gathered}
\alpha_{f l}=\xi_{f l}-\delta_{f}=\tan ^{-1}\left[(v+r a) /\left(u+r t_{w} / 2\right)\right]-\delta_{f} \\
\alpha_{f r}=\xi_{f r}-\delta_{f}=\tan ^{-1}(v+r a) /\left[u-r t_{w} / 2\right]-\delta_{f} \\
\alpha_{r l}=\xi_{r l}=\tan ^{-1}\left[(v-r b) /\left(u+r t_{w} / 2\right)\right] \\
\alpha_{r r}=\xi_{r r}=\tan ^{-1}\left[(v-r b) /\left(u-r t_{w} / 2\right)\right]
\end{gathered}
$$

Wheel load transfer is included in the calculation of tire normal forces. Only the effect caused by roll motion of sprung mass is included in the derivation of load transfer equations. Wheel normal load can be approximated as follows:

$$
\begin{aligned}
F_{z_{f j}}= & \frac{b m g}{2 L}+\frac{h_{g} m_{s} \hat{a}_{x}}{2 L} \mp \frac{m_{s} a_{y}}{t_{w}} \\
& \left(\frac{b}{L} H_{R C}+\frac{K_{\phi f}}{K_{\phi f}+K_{\phi r}} h_{j}\right), \quad j=l, r \\
F_{z_{r j}}= & \frac{a m g}{2 L}-\frac{h_{g} m_{s} \hat{a}_{x}}{2 L} m \frac{m_{s} a_{y}}{t_{w}} \\
& \left(\frac{a}{L} H_{R C}+\frac{K_{\phi r}}{K_{\phi f}+K_{\phi r}} h_{j}\right), \quad j=l, r
\end{aligned}
$$

where the + and - signs are applicable to the rightand left-side wheels, respectively. $\hat{a}_{x}$ is the estimated longitudinal acceleration according to the estimated longitudinal speed.

A modified Dugoff tire model [15] is used in the estimation. Calculation of lateral tire force in Dugoff-tire model can be summarized as follows:

$$
F_{y}=C_{\alpha} \frac{\tan \alpha}{1+s} f(\lambda)
$$

where $\lambda$ is related to tire/road friction coefficient $\mu$. Virtual force on tire $F_{z}$ and function $f(\lambda)$ are defined, respectively, as follows:

$$
\begin{array}{r}
\lambda=\frac{\mu F_{z}(1+s)}{2 \sqrt{(\kappa s)^{2}+\left(C_{\alpha} \tan \alpha\right)^{2}}} \\
f(\lambda)= \begin{cases}(2-\lambda) \lambda, & \lambda<1 \\
1, & \lambda \geq 1\end{cases}
\end{array}
$$

The modified Dugoff tire model uses the definition of absolute lateral slip ratio and an increase factor to overcome the discrepancies in the calculated lateral force of the peak value and under large slip ratios.
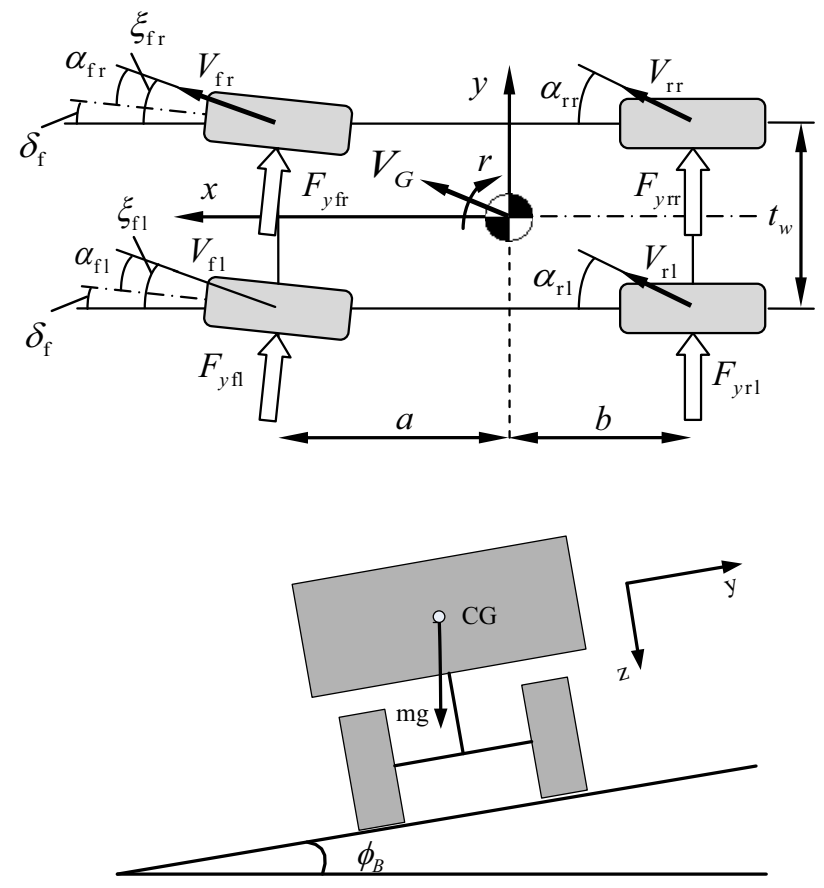

Fig. 1: A 2-DOF vehicle model with four wheels.

\subsection{Architecture of the Estimator}

Lateral acceleration can be calculated by the following equation:

$$
a_{y}=\dot{v}+u r+g \sin \phi_{B}
$$

Road bank can be estimated from Equation (12) as follows when motion mode of the vehicle is static [16] because $\dot{v}$ is zero at steady states.

$$
\phi_{B, S}=\sin ^{-1}\left[\left(a_{y}-r u\right) / g\right]
$$

where $\phi_{B, S}$ is called a static road bank angle.

However, static bank angle is not applicable to transient states because measurement of lateral acceleration includes a disturbance component caused by road bank angle. Therefore, in this study, we apply a dynamic simplex method to estimate dynamic road bank and vehicle sideslip angle. The work presented here is based on modifications to the original version of the dynamic simplex algorithm (DSA) in [17], which is an iterative algorithm with variables that can be scaled to regularize it.

Unlike the traditional Nelder-Mead simplex method and other optimization algorithms, a convergence criterion is not required in the proposed algorithm. The DSA uses fixed-sized simplices, and no operations other than reflection are used. Therefore, each reflected simplex is also a regular simplex. Interested readers can refer to [17] for more details about this version of DSA. The schematic explanation and flowchart of performing DSA are shown in Figs 2 and 3. 


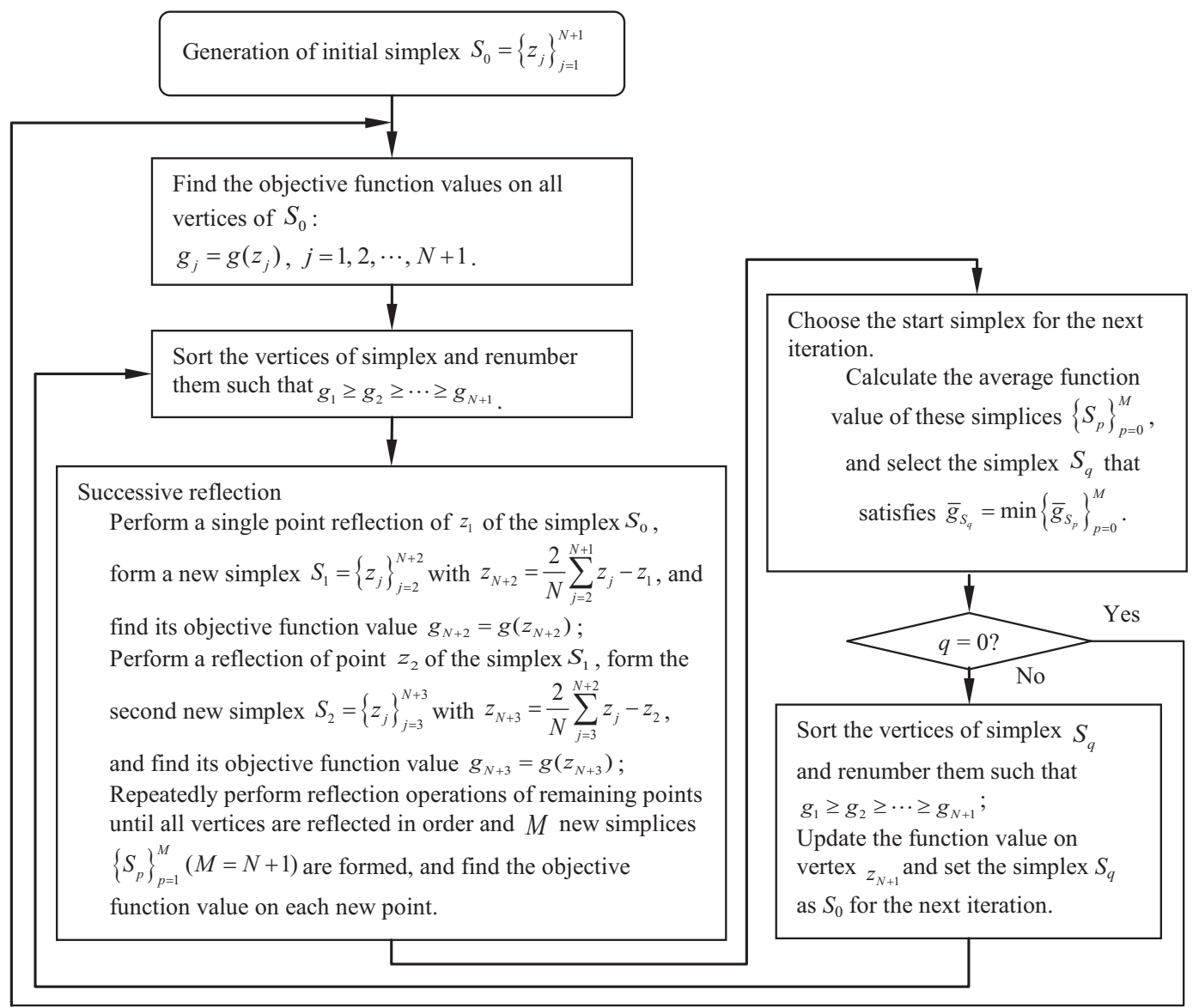

Fig. 2: Flowchart of modified DSA.

The road bank and sideslip angles are used as optimization variables. The higher the accuracy of these variables, the closer the estimated vehicle lateral acceleration $\hat{a}_{y}$ and yaw acceleration $\hat{\dot{r}}$ will be to the measured values $a_{y, m}$ and $\dot{r}_{m}$. The squared error between the predictions and measurements is consequently utilized as an objective function.

The optimization model is described as follows:

$$
\left\{\begin{array}{l}
\mathbf{X}=\left[\phi_{B}, \beta\right] \\
\min f(\mathbf{X})=\rho\left(\hat{a}_{y}-a_{y, m}\right)^{2}+\left(\hat{\dot{r}}-\dot{r}_{m}\right)^{2} \\
\text { s.t. } \phi_{B \min } \leq \phi_{B} \leq \phi_{B \max } \\
\quad \beta_{\min } \leq \beta \leq \beta_{\max }
\end{array}\right.
$$

Violation of the constraints in (14) is processed using penalty functions, which are given as follows:

$$
f_{p \phi}= \begin{cases}\lambda_{\phi}\left(\phi_{B, \min }-x_{1}\right), & \text { if } x_{1}<-\phi_{B, \max } \\ 0, & \text { if }-\phi_{B, \max } \leq x_{1} \leq \phi_{B, \max } \\ \lambda_{\phi}\left(x_{1}-\phi_{B, \max }\right), & \text { if } x_{1}>\phi_{B, \max } .\end{cases}
$$
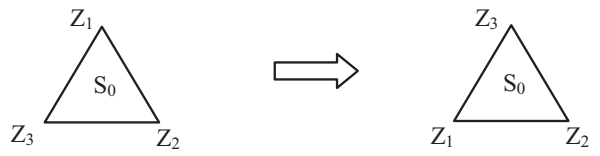

I. Generation of initial simplex

II. Sort and renumber
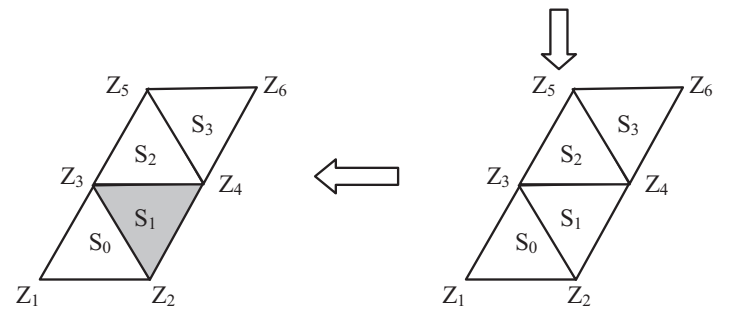

IV. Find $S q$ among all simplices $\quad$ II. Successive reflection

Fig. 3: Schematic explanation of DSA in two-dimensional space.

$$
f_{p \beta}= \begin{cases}\lambda_{\beta}\left(-\beta_{\max }-\eta x_{2}\right), & \text { if } \eta x_{2}<-\beta_{\max } \\ 0, & \text { if }-\beta_{\max } \leq \eta x_{2} \leq \beta_{\max } \\ \lambda_{\beta}\left(\eta x_{2}-\beta_{\max }\right), & \text { if } \eta x_{2}>\beta_{\max }\end{cases}
$$




\begin{tabular}{clll}
\multicolumn{4}{c}{ Table 1: Parameters Used in DSA } \\
\hline Parameter & Value & Parameter & Value \\
\hline 1 & 0.025 & $\lambda_{\phi}$ & 15 \\
$\rho$ & 1.0 & $\phi_{B, \max }$ & 0.45 \\
$\eta$ & 0.75 & $\beta_{\max }$ & 0.2 \\
$\lambda_{\beta}$ & 15 & & \\
\hline
\end{tabular}

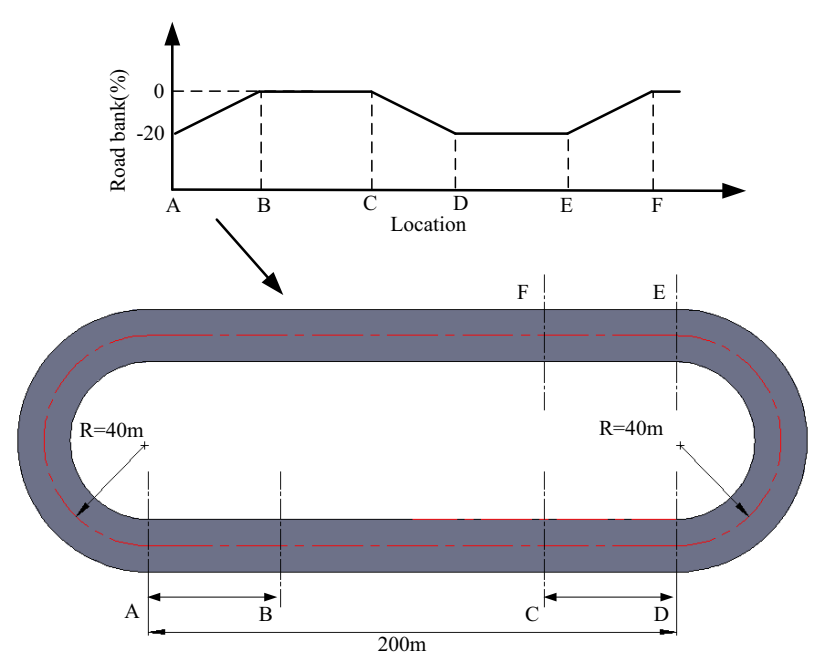

Fig. 4: The virtual ground for tests.

By adding $f_{p \phi}$ and $f_{p \beta}$ to $f(\mathbf{X})$, the final objective function becomes $g(\mathbf{X})=f(\mathbf{X})+f_{p \phi}+f_{p \beta}$, which is an optimization model without constraints.

The simplex size should be properly chosen and sufficiently large to keep up with the moving optimum. Oversized simplices usually result in large estimation errors. Therefore, a trade-off exists between dynamic response and static accuracy of the estimation. We carefully tune the simplex size by trial and error.

The estimator parameters are listed in Table 1.

\section{Simulation Test}

The estimator is evaluated using TruckSim and Matlab. A bus model with non-linear suspension is built into TruckSim, which assumes that the bus is equipped with virtual sensors to measure the steering wheel angle, wheel speeds, yaw rate, and lateral acceleration. The simulation is conducted with a driver model. Estimated results of road bank and vehicle sideslip angle are compared with those measured by virtual sensors.

Transient maneuver on a variable banked road is simulated to verify the proposed estimator (Fig. 4). The bus runs on a $200 \mathrm{~m}$ long oval road with $40 \mathrm{~m}$ radius, and the road bank dynamically changes between $-20 \%$ and $0 \%$ at the transition areas between linear and circular

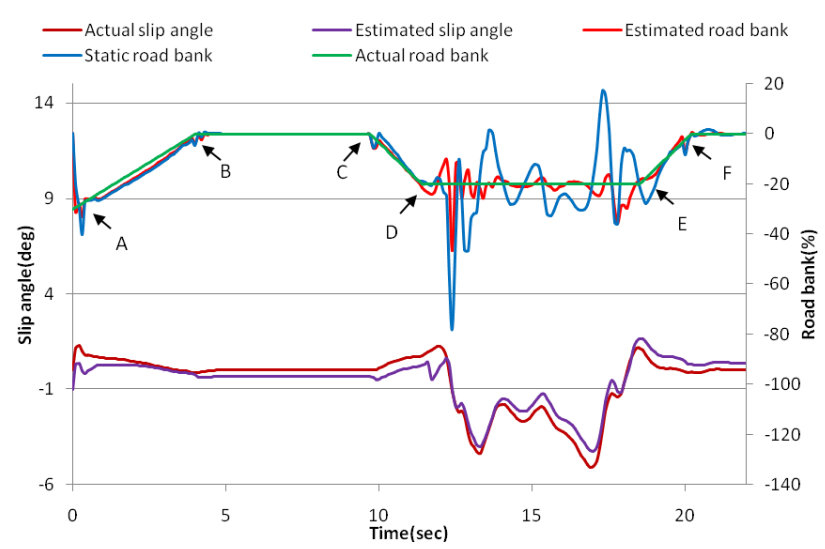

Fig. 5: Estimated results on high friction surface.

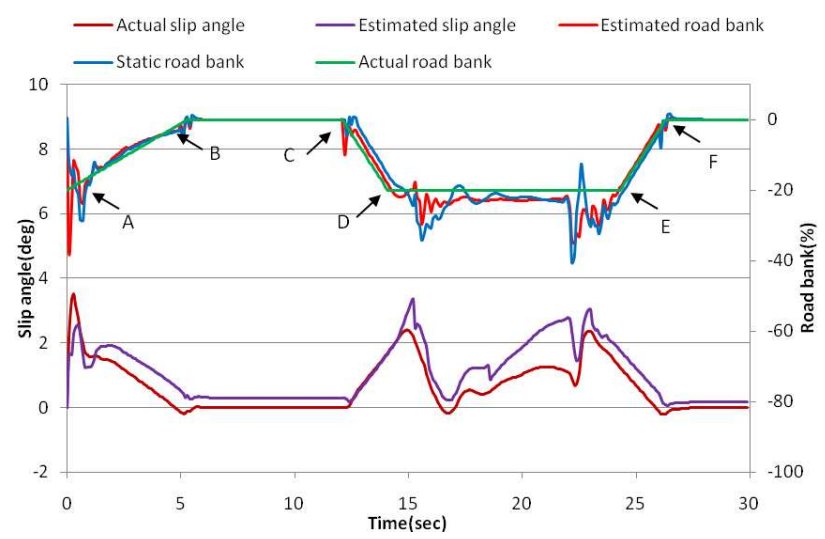

Fig. 6: Estimated results on low friction surface.

parts. The initial road bank is set at $-20 \%$ starting from location A.

\subsection{Maneuver on high friction road surface}

The friction coefficient and the target vehicle speed in this driving scenario are set to 0.85 and $50 \mathrm{~km} / \mathrm{h}$, respectively. Estimated results of road bank and vehicle sideslip angle are compared with those measured by the bus model (Fig. $5)$.

Both sideslip angle and road bank varied in transient regions (Fig. 5). Comparison of estimated road bank using DSA and static bank angle calculated using Equation (10) indicates that the static bank angle contains significant bias when vehicle is turning. The estimated vehicle sideslip angle agrees with its actual value, in contrast to the estimated road bank that follows the actual value with a higher accuracy. 


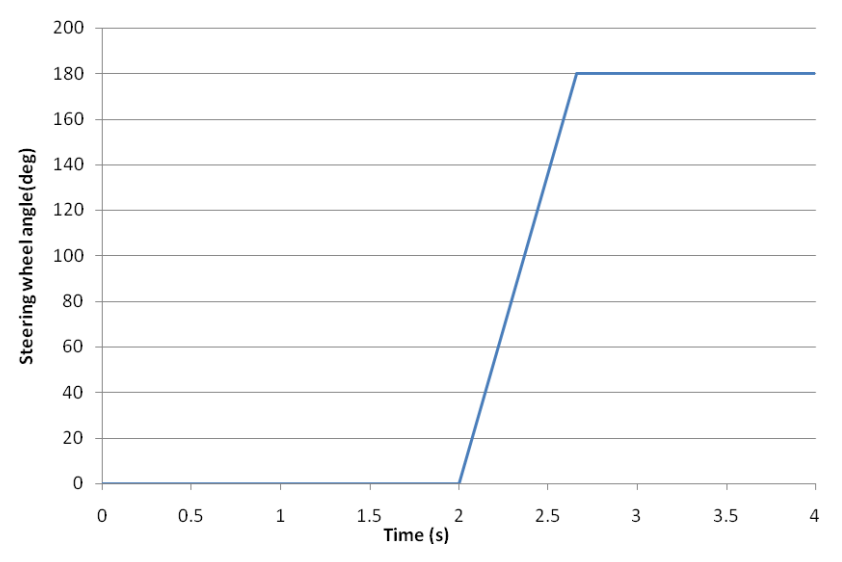

Fig. 7: Steering wheel angle of step-steer.

\subsection{Maneuver on low friction road surface}

This maneuver is performed on a road surface with a friction coefficient of 0.4 and target vehicle speed of 30 $\mathrm{km} / \mathrm{h}$. Simulation results are shown in Fig. 6 .

The estimation errors of road bank angle in this low friction case using DSA and static bank angle calculated using Equation (13) are less than those on a high friction road surface because of the smaller amplitude of vehicle lateral response. The proposed estimator still has a higher accuracy than the static bank angle calculation.

\section{Rollover Prediction with Bank Angle}

Many warning systems use a prediction algorithm based on the values of vehicle roll angle and/or lateral acceleration. NHTSA uses the Static Stability Factor (SSF) [18]. However, this factor does not consider the effects of bank angle. Thus, it may not warn drivers even when a vehicle rollover happens on a bank angle curve.

A dynamic roll stability limit (RSL), which indicates the maximum stable lateral acceleration, is proposed in this study. The proposed RSL changes with the road bank.

The resultant moments about the outer tire contact point in roll plane (Fig.7) is given as

$$
\sum M_{o}=K_{\phi} \phi+F_{y, R C} H_{R C}-F_{z, R C} t_{w} / 2+F_{i, z} t_{w}=0
$$

Equations (1) and (2) under the small angle assumption become

$$
\begin{aligned}
& F_{y, R C}=m_{s} a_{y}-m_{s} g \phi_{B} \\
& F_{z, R C}=m_{s} g+m_{s} a_{y} \phi_{B}
\end{aligned}
$$

The vertical force on the inner wheels $F_{i, z}$ becomes zero as the inner wheel lifts off. Hence, lateral acceleration and roll angle in this case (named $a_{y \max , \phi}$

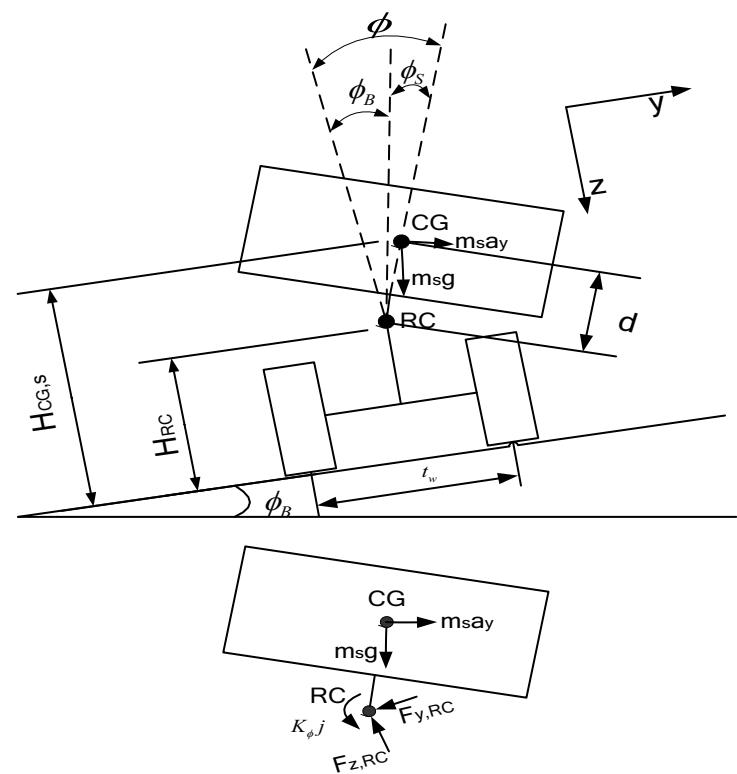

Fig. 8: Schematic representation of suspended vehicle model.

and $\left.\phi_{\max , \phi}\right)$ are as follows:

$$
\begin{aligned}
K_{\phi} \phi_{\max , \phi}= & -\left(m_{s} a_{y \max , \phi}-m_{s} g \phi_{B}\right) H_{R C} \\
& +\left(m_{s} g+m_{s} a_{y \max , \phi} \phi_{B}\right) \frac{t_{w}}{2} \\
\sum M_{R C}= & m_{s} a_{y} d \cos \phi_{S}+m_{s} g d \sin \phi_{S}-K_{\phi} \phi=0
\end{aligned}
$$

According to the geometrical relationships shown in Figure 7,

$$
d=\left(H_{C G, s}-H_{R C}\right) / \cos \phi
$$

By assuming small angles, Equations (21) and (22) become

$$
K_{\phi} \phi \approx m_{s} a_{y} m+m_{s} g d\left(\phi-\phi_{B}\right)
$$

Substituting Equation (23) into Equation (20) and using the definition of the roll gain,

$$
\frac{a_{y \max , \phi}}{g}=\frac{\phi_{B}\left[H_{C G, s}+\left(H_{C G, s}-H_{R C}\right) R_{\phi}\right]+\left(t_{w} / 2\right)}{H_{C G, s}+\left(H_{C G, s}-H_{R C}\right) R_{\phi}-\phi_{B}\left(t_{w} / 2\right)}
$$

For a rigid vehicle model $\left(\mathrm{H}_{\mathrm{CG}, \mathrm{s}}=\mathrm{H}_{\mathrm{CG}}\right)$, road bank disturbance is neglected $\left(\phi_{B}=0\right)$, and Equation (24) becomes the SSF form described by Equation (25).

$$
a_{y \max , \phi} / g=t_{w} /\left(2 H_{C G}\right)
$$

The performance of the proposed RSL is evaluated by a set of rollover maneuvers compared with SSF. The moment when the vertical force of the inner wheel becomes zero or lifts off is marked by a vertical line in the following related figures. The tire that leaves the ground earlier is chosen and compared with the lateral acceleration. 


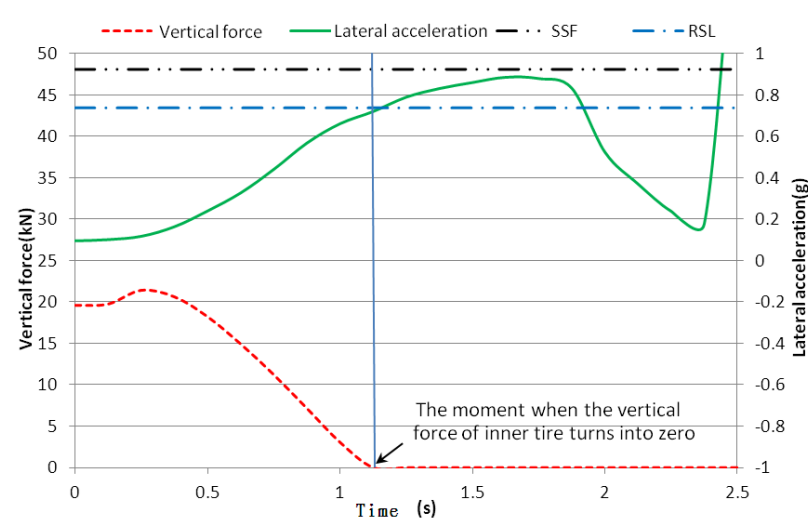

Fig. 9: Step-steer at $80 \mathrm{~km} / \mathrm{h}$ on road bank $10 \%$.

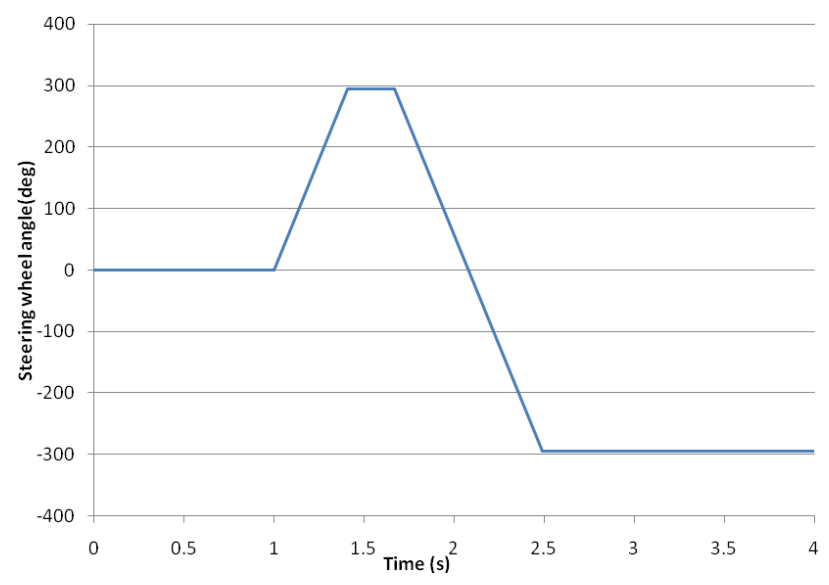

Fig. 10: Steering wheel angle of Fishhook steering.

\subsection{Step-steer Maneuver}

The steering wheel angle is $180^{\circ}$, and the initial vehicle speed is $80 \mathrm{~km} / \mathrm{h}$ in step-steer maneuver with a road bank of $10 \%$ (Fig. 8). The vertical force of the inner wheel and lateral acceleration are shown in Fig. 9. The vertical line in each diagram indicates the approximate time when the vertical force of the inner wheel becomes zero. When the vertical force of the inner wheel falls below zero, the lateral acceleration exceeds the value of RSL almost simultaneously. The value of lateral acceleration also does not exceed the value of SSF threshold, which does not reflect that the vertical force of the inner wheel has become zero and does not warn the driver of a possible crash.

\subsection{Fishhook Maneuver}

The NHTSA Fishhook is one of the standard rollover maneuvers on a road bank of $10 \%$. The steering wheel angle of the maneuver is shown in Fig. 10. The vertical

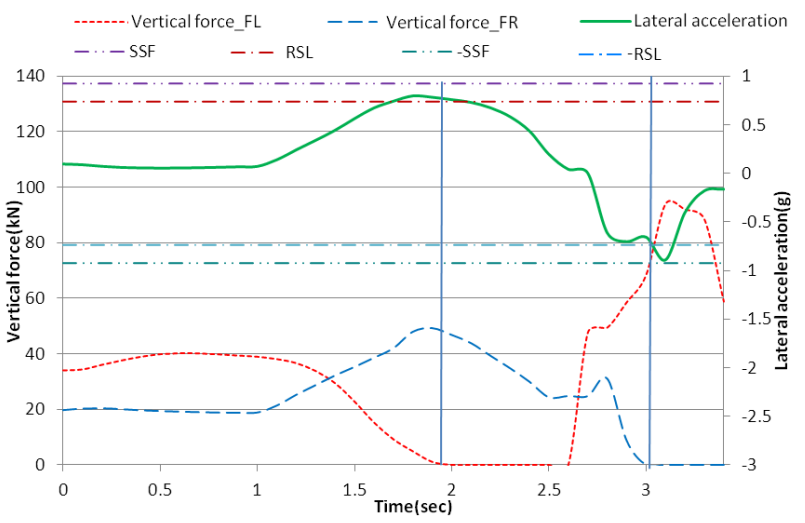

Fig. 11: Fishhook maneuver at $60 \mathrm{~km} / \mathrm{h}$ on road bank $10 \%$.

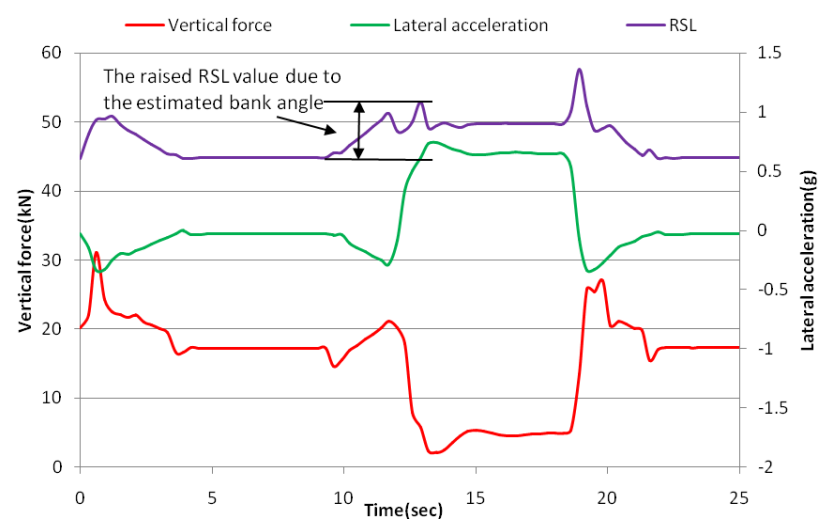

Fig. 12: Maneuver at $50 \mathrm{~km} / \mathrm{h}$ with a variant road bank.

tire forces on both sides, as well as the comparison of lateral acceleration and its threshold, are illustrated in Fig. 11. Lateral acceleration slightly exceeds the value of RSL when the vertical force of the left front tire becomes zero. However, the bus does not roll over until the second steering. The vertical force of the right front tire becomes zero when the lateral acceleration exceeds the threshold value.

\subsection{Maneuver on a dynamic banked road}

The calculated RSL is based on the estimation results on high friction surfaces (Fig. 12). The value of the proposed RSL dynamically changes with varying road bank. The lateral acceleration does not exceed the increased RSL value because of the estimated bank angle, and a possible false alarm at point $\mathrm{A}$ is avoided. 


\section{Conclusions}

In this paper, a dynamic road bank estimator using DSA is first built, and its performance is evaluated using a transient maneuver on a variant banked road in TruckSim software. Simulation results show that the estimated road bank sufficiently tracks the actual value on both high- and low-friction road surfaces. The estimation is then used in rollover prediction, and the simulation result shows more accurate and reliable predictions.

Future work may include the evaluation of the road bank estimation from the driver's perspective in loop simulator or road tests.

\section{Appendix}

Table 2 and Table 3 show the subscripts as well as the variables and parameters used in this paper, respectively.

Table 2: Subscripts

\begin{tabular}{cl}
\hline Subscripts & Definitions \\
\hline$f$ & Front axle \\
$l$ & Left side of vehicle \\
$r$ & Rear axle or left side of vehicle \\
$f l$ & Front left \\
$f r$ & Front right \\
$r l$ & Rear left \\
$r r$ & Rear right \\
\hline
\end{tabular}

\section{Acknowledgement}

Foundation item: Grants No.50908008 supported by the National Natural Science Foundation of China.

\section{References}

[1] National Highway Traffic Safety Administration (NHTSA), Initiative to address the mitigation of vehicle rollover, Docket No. NHTSA-2003-14622-1, (2003).

[2] A. I. Aggour, F. E. Attounsi, Fuzzy Topological Properties on Fuzzy Function Spaces, Applied Mathematics \& Information Sciences Letters, 1, 1-5 (2013).

[3] Z. B. Walters, Quantum Coherent Dynamics at Ambient Temperature in Photosynthetic Molecules, Quantum Physics Letters, 1, 21-33 (2012).

[4] M. S. H. Shirvani, H. Alinejad-Rokny, Performance Assessment of Feasible Scheduling Multiprocessor Tasks Solutions by using DEA FDH method, Information Sciences Letters, 1, 61-66 (2012).

[5] W. Luo, J. Xiao, Q. Lu and P. Li, Rolling Ball Detection for Signs in Aircraft Measurement, Appl. Math. Inf. Sci., 6, 925S-933S (2012).
Table 3: Variables and Parameters

\begin{tabular}{|c|c|}
\hline Variables & Definitions \\
\hline$a$ & Distance between vehicle COG and front axle \\
\hline$a_{y}$ & Lateral acceleration of vehicle \\
\hline$a_{y \max , \phi}$ & Threshold value of lateral acceleration at wheel lift off \\
\hline$a_{y, m}$ & Measured lateral acceleration \\
\hline$b$ & Distance between vehicle COG and rear axle \\
\hline$d$ & Distance from COG of sprung mass to roll axis \\
\hline$f$ & Objective function of optimization \\
\hline$f_{p \beta}$ & Penalty function for constraint of sideslip angle \\
\hline$f_{p \phi}$ & Penalty function for constraint of road bank \\
\hline$F_{y}$ & Lateral tire force in tire y-axis(of wheel plane) \\
\hline$F_{z}$ & Vertical force on tire \\
\hline$F_{i, z}$ & Vertical force on the inner wheel \\
\hline$g$ & $\begin{array}{l}\text { Objective function with penalty functions added; } \\
\text { acceleration of gravity }\end{array}$ \\
\hline$h_{\phi}$ & COG height of sprung mass respect to roll axis \\
\hline$H_{R C}$ & Height of roll axis respect to grand \\
\hline$H_{C G, s}$ & COG height of sprung mass respect to grand \\
\hline$I_{z}$ & Yaw moment of inertia (about vehicle $\mathrm{z}$-axis) \\
\hline$K_{\phi}$ & Roll stiffness of suspension \\
\hline$L$ & Wheel base, $\mathrm{L}=\mathrm{a}+\mathrm{b}$ \\
\hline$m$ & Total vehicle mass \\
\hline$m_{s}$ & Spung mass \\
\hline$N$ & Dimension of the DSA space \\
\hline$r$ & Yaw rate \\
\hline$R_{w}$ & Wheel radius \\
\hline$R_{\phi}$ & Roll gain \\
\hline$S$ & Simplex \\
\hline$t_{w}$ & Wheel track \\
\hline$u$ & Longitudinal speed \\
\hline$v$ & Lateral speed \\
\hline$V$ & Wheel speed \\
\hline$V_{G}$ & Velocity vector at vehicle COG \\
\hline$V_{\max }$ & Maximum stable vehicle velocity \\
\hline$z$ & Vertex of simplex \\
\hline$\alpha$ & Tire sideslip angle \\
\hline$\beta$ & Vehicle sideslip angle at COG \\
\hline$\delta_{f}$ & Steer angle at front wheels \\
\hline$\phi$ & Vehicle roll angle \\
\hline$\underset{\phi_{B}}{\phi_{\max , \phi}}$ & $\begin{array}{l}\text { Threshold value of roll angle at wheel lift off } \\
\text { Road bank angle }\end{array}$ \\
\hline$\phi_{B, S}$ & Static road bank angle \\
\hline$\phi_{S}$ & Sprung mass roll angle \\
\hline$\eta$ & Scale for vehicle sideslip angle at COG \\
\hline$\lambda_{i}$ & Coefficients for penalty functions $(i=\phi, \beta)$ \\
\hline$\mu$ & Tire/road friction coefficient \\
\hline$\rho$ & Weight for lateral acceleration in optimization model \\
\hline
\end{tabular}

[6] G. J. Forkenbrock, W. R. Garrott, M. Heitz and B. C. O'hara, An experimental examination of $\mathrm{j}$-turn and fishhook maneuvers that may induce on-road, untripped, light vehicle rollover, SAE Paper, no.2003-01-1008, (2003).

[7] National Highway Traffic Safety Administration, Traffic Safety Facts 1998: A Compilation of Motor Vehicle Crash Data from the Fatality Analysis Reporting System and General Estimates System, NCSA Advanced Research and 
Analysis, (1999).

[8] S. Rakheja and A. Piche, Development of Directional Stability Criteria for an Early Warning Safety Device, SAE Paper, no.902265, (1990).

[9] H. E. Tseng, X. Li and D. Hrovat Estimation of Land Vehicle Roll and Pitch Angles, Vehicle System Dynamics 45, 433443 (2007).

[10] R. J. Jihan and C. Gerdes, Estimation of Vehicle Roll and Road Bank Angle, American Control Conference, (2004).

[11] K. H. Senger and W. Korturn, Investigations on State Observers for the Lateral Dynamics of Four-Wheel Steered Vehicles, The Dynamics of Vehicles on roads and on tracks, Proceedings of 11th IAVSD Symposium, Supplement to Vehicle System Dynamics, 18, 515-527 (1989).

[12] L. R. Ray, Nonlinear State and Tire Force Estimation for Advanced Vehicle Control, IEEE Transactions on Control Systems Technology, 3, 117-124 (1995)

[13] Mechanical Simulation Corp., TruckSim Software Help [EB/OL].

[14] H. B. Pacejka, Tyre and Vehicle Dynamics, Butterworth Heinemann Woburn, MA, USA, (2002).

[15] N. Ding and S. Taheri, A Modified Dugoff Tire Model for Combined-slip Forces, Tire Science and Technology, 38, 228-244 (2010).

[16] H. E. Tseng and T. Brown, The development of vehicle stability control at Ford, IEEE/ASME Transactions on Mechatronics, 4, 307-328 (1999).

[17] Q. Xiong and A. Jutan, Continuous optimization using a dynamic simplex method, Chemical Engineering Science, 58, 3817-3828 (2003).

[18] J. Yoon, W. CHO, J. Kang, B. Koo and K. Yi, Design and evaluation of a unified chassis control system for rollover prevention and vehicle stability improvement on a virtual test track, Control Engineering Practice, 18, 585-597 (2010).

[19] Sunny Chauhan, Common Fixed Point Theorems on Fuzzy Metric Spaces Using Implicit Relation, Mathematical Sciences Letters, 1, 89-96 (2012).

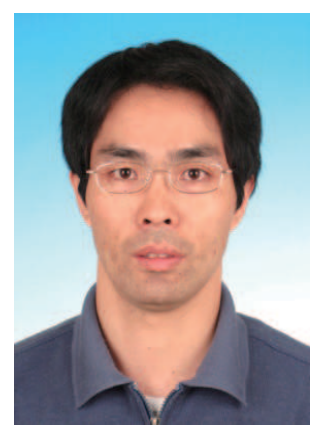

\section{Guizhen Yu}

is an Associate Professor in Beihang University and has received the B.S., M.S. and Ph.D. degree from the Jilin University, Changchun, China, In 1997, 2000 and 2003 respectively. His research interests include vehicle safety warning \& control and intelligent vehicle.

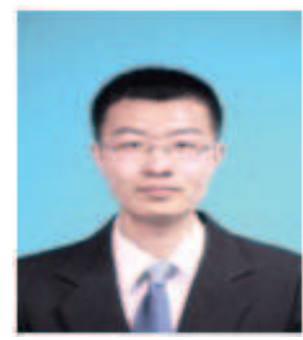

\section{Di Wang}

is a PhD student in Beihang University. He received the bachelor's degree in Tsinghua University for vehicle engineering. His research interests are intelligent vehicle safety and control.

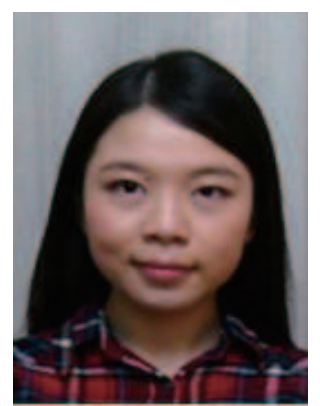

\section{Qin Li}

is a master student in Beihang University. She received the bachelors degree in Beihang University.Her main research interests are vehicle safety and control. She has published research articles in related study areas.

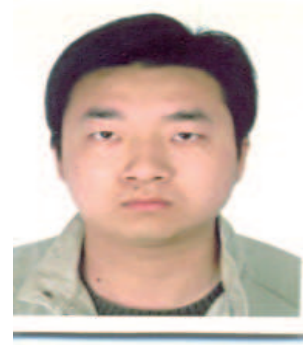

\section{Pangwei Wang}

is a PhD student in Beihang University. He received the masters degree in Tai Yuan University of Technology for control theory and control engineering. His research interests are in the areas of Cooperative Vehicle Infrastructure Systems and Safety Control including the mathematical methods and models for control systems. He has published extensively in internationally refereed journals in related study areas.

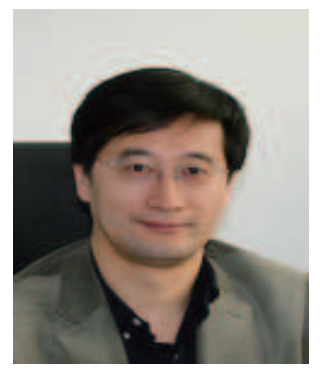

\section{Yunpeng Wang}

is Professor of Beihang University.He is dean of College of TrafficScience $\&$ Engineering and director of Beijing Key Laboratory for Cooperative Vehicle Infrastructure Systems and Safety Control. He was the executive director of China Highway and Transportation Society. He is referee and Editor of the 4th China Journal of Highway and Transport. His research interests are in the areas of traffic planning and Intelligent Transportation System. He has published extensively in internationally refereed journals. 